\title{
THERMODYNAMIC CONSIDERATION OF THE RETENTION MECHANISM IN A POLY(PERFLUOROALKYL ETHER) GAS CHROMATOGRAPHIC STATIONARY PHASE USED IN PACKED COLUMNS
}

\author{
CONSIDERACIONES TERMODINAMICAS ACERCA DEL MECANISMO DE RETENCION \\ EN UN POLI(PERFLUOROALQUIL ETER) UTILIZADO COMO FASE ESTACIONARIA \\ EN COLUMNAS RELLENAS PARA CROMATOGRAFIA GASEOSA
}

R. C. Castells ${ }^{1}$, L. M. Romero and A. M. Nardillo ${ }^{1}$

\begin{abstract}
SUMMARY
Retention volumes of fifteen hydrocarbons were measured in columns containing several concentrations of a commercial poly(perfluoroalkyl ether), Fomblin Y HVAC 140/13, as the stationary phase. Two different type of packing were studied: one of them employed pre-silylated Chromosorb P AW DMCS as the solid support, and the other type was prepared by coating the stationary phase on Chromosorb $P A W$ and silylating on-column. On-column silylated columns showed unequivocal symptoms of partial deactivation; retention volumes changed regularly with the content of stationary phase in pre-silylated columns. Analysis of retention in pre-silylated columns indicates that a mixed mechanism (partition and adsorption on the gas-liquid interface) is operative. Systems hydrocarbon + perfluorocompound show pronounced positive deviations from the ideal behaviour that can be attributed to repulsion between the hydrocarbon and the perfluorocompund segments.
\end{abstract}

Keywords: Gas chromatography, Poly(perfluoroalkyl ether), hidrocarbons, adsorption on liquid surfaces, mixed retention

\section{INTRODUCTION}

Perfluorinated substances have been sporadically employed as stationary phases in gas chromatography, and this mostly for the separation of substances of high chemical reactivity or

\footnotetext{
${ }^{1}$ Miembro de la Carrera del Investigador del CONICET, UNLP
} 
perfluorocompounds and freons. Excellent review articles have been written by Pomaville and Poole [1] and by O'Mahony et al.[2].

Highly fluorinated fluids are characterized by their chemical inertia and by very weak molecular interactions, either at the pure state or in their mixtures with other substances. Cohesive energy densities of perfluoroalkanes and perfluorocycloalkanes are much less than those of the corresponding hydrocarbons [3], and although fluorocarbons and hydrocarbons are individually highly non polar, their mixtures show important deviations from Raoult's law [3-5]. These properties have two important consequences in relation with their use as gas chromatographic stationary phases. On one side, as pointed out by Poole and collaborators $[1,6,7]$, retention times in highly fluorinated stationary phases shall be shorter than in conventional phases, thus enabling the separation of low volatility or thermally labile substances.

On the other side, weak interactions with the solid support or the capillary wall result in insufficient surface deactivation, uneven distribution and poor film stability, reflected in peak asymmetry, low efficiency and retention time variations; all of these deleterious symptoms are very markedly displayed in using perfluoroparaffins.

Drastic improvements in the chromatographic behaviour is obtained by incorporating polar groups in the stationary phase molecules. The poly(perfluoroalkyl ether) phase Fomblin $\mathrm{YR},\left[\left(\mathrm{OCFCF}_{3} \mathrm{CF}_{2}\right)_{\mathrm{n}}-\left(\mathrm{OCF}_{2}\right)_{\mathrm{m}}\right]$, was introduced in 1983 by Dhanesar and Poole [6,7]; paraffinic and olefinic hydrocarbons, injected at temperatures markedly lower than their boiling points, elute from these columns in short retention times, with very good peak shapes, but asymmetric peaks are obtained for solutes of higher polarity. Furthermore, the authors found that packings prepared by coating previously silylated supports (Gas-Chrom Q) gave symmetrical peaks when tested at low temperatures, but after heating to above $100{ }^{\circ} \mathrm{C}$ and returning to low temperatures for re-testing, shorter retention times and asymmetric peaks were obtained, a behaviour that the authors attribute to film contraction, that results in bare surface exposition and liquid lenses. Columns stable at temperatures higher than $200{ }^{\circ} \mathrm{C}$ and with efficiencies similar to those obtained for conventional phases were obtained by coating Chromosorb $\mathrm{P}$, packing the columns with coated support, and on-column silylating by injection of Silyl-8 or bis(trimethylsilyl)trifluoroacetamide (BSTFA) [6,7].

Mixtures of fluorocarbon compounds and aliphatic or alicyclic hydrocarbons are the only known example of systems with large positive excess functions where none of the components is polar; as such, they have been the subject of many studies since the 1950s [8,9]. Although these trends are qualitatively consistent with the large differences in cohesive energy density of fluorocarbons and hydrocarbons, the solubility parameter approach does not give a satisfactory quantitative explanation [3]. Plots of surface tension against composition also show pronounced deviations from the ideal behaviour [10,11]. The objective of the present paper is to obtain thermodynamic data for the processes of solution and adsorption on the gasliquid interface for a group of hydrocarbons at infinite dilution in a highly fluorinated stationary phase in the neighbourhood of room temperature. A high molecular weight perfluoroalkane was supposed to be used as the solvent, according with the original plan; the poor performance of these substances as stationary phases compelled us to modify the project. Fomblin was then chosen because of its characteristics and to profit from the experience collected by Poole and his group on this stationary phase. 


\section{EXPERIMENTAL SECTION}

Materials and columns. Fomblin Y HVAC 140/13 (weight average molecular weight 6500) and 1,1,2-trichlorotrifluoroethane (Freon 113) were purchased from Aldrich; BSTFA was obtained from Supelco. Hydrocarbon solutes of different origins, all of them more than 99\% pure, were used as received. Column packings were prepared in a rotary evaporator, using Freon 113 as solvent. Coated supports were packed into $0.53 \mathrm{~cm}$ i.d. and $1.0 \mathrm{~m}$ in length stainless steel tubes with the aid of vacuum suction and gentle tapping. Two sets of columns were prepared:

a) On-column silylated columns: a packing containing $5.67 \%$ by weight of Fomblin on Chromosorb P AW 60/80 was prepared by the above mentioned method. A $1.80 \mathrm{~m} \times 0.4 \mathrm{~cm}$ i.d. glass column containing this packing was installed in a Konik gas chromatograph (see later) with a glass lined injector; the injector and the column oven were set to 100 and $150^{\circ} \mathrm{C}$, respectively, and on-column silylation was performed by slowly injecting $100 \mu \mathrm{L}$ of BSTFA with a nitrogen flow rate of $5 \mathrm{ml} / \mathrm{min}$. The column was held at $150^{\circ} \mathrm{C}$ for several hours, and the silylating treatment was then repeated after reversing the column end connections. The column was carefully emptied and its content was used as starting material to prepare packings with higher stationary phase concentrations, by successively adding Fomblin by the above mentioned coating technique. By this method four columns containing 5.67, 8.30, 13,36 and 22.05 by weight percentage (w) of Fomblin on the same lot of solid support were prepared, with the objective of minimizing unpredictable effects associated with the silylating process.

b) Pre-silylated columns, containing $4.29,5.56,7.50,10.89,15.52$ and $19.40 \%$ by weight of Fomblin were prepared using Chromosorb P AW DMCS 60/80 as the solid support.

Apparatus and procedure. The study of thermal stability of packings was performed in a Konik 3000 gas chromatograph, equipped with a FID and a Spectra Physics Datajet Integrator, using $1.50 \times 2 \mathrm{~mm}$ i.d. glass columns.

A home assembled apparatus, in which column temperature was controlled to better than $\pm 0.05^{\circ} \mathrm{C}$ by immersion in a water bath, was used for the remaining measurements. Nitrogen, successively passed through a molecular sieves trap (Davidson 5A), a Brooks 8606 pressure regulator, a Brooks 8743 flow controller and a $2 \mathrm{~m}$ x 1/8" o.d. coiled copper tube immersed in the column bath, was used as the carrier gas. Inlet pressures were measured by means of a mercury manometer at a point between the copper coil and a Swagelok 1/4" s.s. "T"; one branch of this last was provided with a septum, and the columns were connected to the remaining branch. Solute vapours were on-column injected by using Hamilton syringes. Eluates were detected with a Hewlett-Packard 5750 FW and electrometer signals were fed to a Hewlett-Packard 3396A integrator. Flow rates ranging between 15 and $30 \mathrm{ml} / \mathrm{min}$ were measured by means of a water jacketted soap film flow meter.

Sample sizes of the order of $10^{-2} \mu$ mole resulted in symmetrical peaks for all the studied solutes, thus warranting Henry's law conditions for all the retention mechanisms. Aromatic hydrocarbons, whose peaks displayed a slight asymmetry that persisted at the smallest sample sizes compatible with instrumental noise, were excluded from this study. Solute vapours and a small methane sample were simultaneously injected; net retention times were measured to $10^{-3}$ min between the maxima of the solute and the methane peaks. Specific retention volumes $\left(V_{g}^{\circ}\right)$ 
and net retention volumes per gram of packing $\left(V_{N}\right)$ were calculated from values of the operating parameters in the usual form [12]. Values at each temperature were means of no less than four injections; retentions were measured for groups of 3-4 solutes at five temperatures equally spaced within the range $22-35^{\circ} \mathrm{C}$, and the measurements for the same group of solutes were repeated after $2-3$ weeks.

Densities of Fomblin were measured at twelve temperatures between 19 and $41{ }^{\circ} \mathrm{C}$ with a $3 \mathrm{ml}$ pycnometer that had been carefully calibrated through the same temperature interval, and least squares fitted to the following polynomial:

$\rho_{2}\left(t /{ }^{\circ} C\right)=1.94429-1.2808 \times 10^{-3} t-1.30 \times 10^{-5} t^{2}+10^{-7} t^{3}$

The thermal expansion coefficient, as calculated from eq. (1), is $\alpha_{2}=9.15 \times 10^{-4} \mathrm{~K}^{-1}$.

\section{RESULTS AND DISCUSSION}

Comparing pre-silylated and on-column silylated packings. The pattern displayed in Fig. 1 for four representative cases is shared for all the solutes. $V_{N}$ increases in a satisfactory linear fashion with percentage Fomblin in the pre-silylated Chromosorb $P$ phases. $A V_{N}$ fall of concern occurs, particularly with unsaturated solutes, when the Fomblin proportion rises from $5.7 \%$.

A series of alternative suggestions could be advanced to explain the behaviour observed in on-column silylated packings. Identification of the retention mechanisms that operate in these columns and discriminating between their respective contributions to the total retention would be a difficult task, with dubious results. Pre-silylated packings represent a more attractive option when the objective is to isolate the effects of the liquid phase from those of the solid support.

Physical meaning of retention volumes measured in pre-silylated columns, on the other side, could be questioned in terms of the thermal instability of these packings. Therefore, and although retention volumes demonstrated excellent reproducibility in the $22-35^{\circ} \mathrm{C}$ temperature range, a test addressed to check the stability of pre-silylated packings under conditions considerably more stringent than those prevailing during the thermodynamic measurements was performed. $\mathrm{N}$-nonane and $\mathrm{n}$-decane retention volumes were measured at six temperatures between 40 and $75^{\circ} \mathrm{C}$ in columns containing 10.89 and $19.40 \%$ packings; the columns were then slowly heated to $120^{\circ} \mathrm{C}$ and kept for $1.5 \mathrm{~h}$ at this temperature, spontaneously cooled down to room temperature, and heated again to $120^{\circ} \mathrm{C}$ for $1.5 \mathrm{~h}$; retention volumes were then re-measured in the $40-75^{\circ} \mathrm{C}$ interval. The results of this experiment have been gathered in Table $I$, and show that not only the retention volumes measured before and after heating are coincident, but that also the slopes of the plots of $\ln V_{g}^{\circ}$ vs. $1 / \mathrm{T}$ remain constant. The efficiency of both columns is poor and heating seems to produce a drop in the number of theoretical plates of the column containing the $10.89 \%$ packing. Summarizing, there are no counter-indications for the employment of these columns in the measurement of thermodynamic properties, where column efficiency is a desirable but not an essential parameter. 


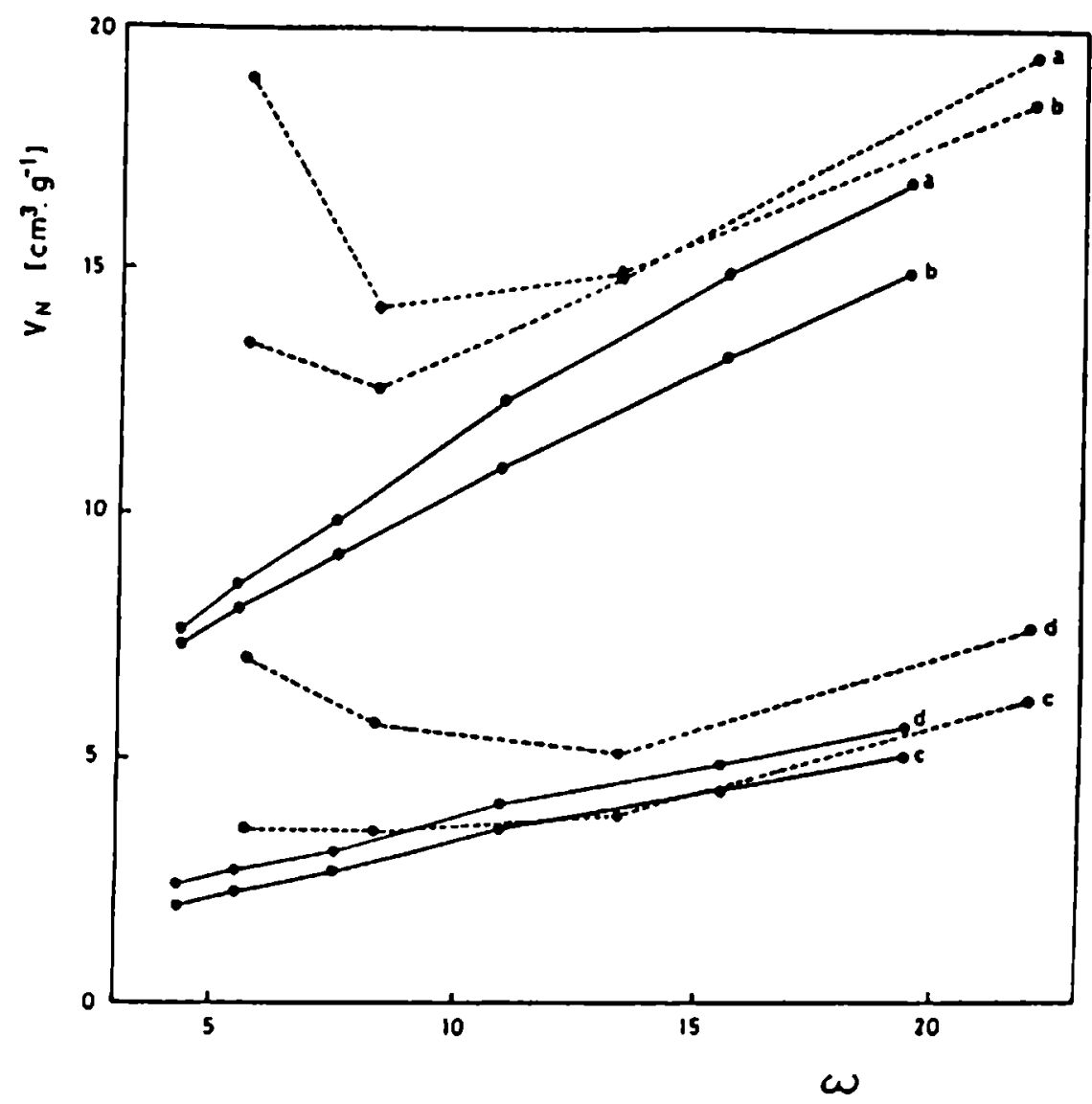

Fig. 1.- Retention volume per gram of packing at $25^{\circ} \mathrm{C}\left(\mathrm{V}_{\mathrm{N}}\right)$ against percentage by weight of stationary phase (w). Dotted lines: on-column silylated packings. Continuous lines: pre-silylated packings. Solutes: (a) n-octane; (b) 1-octene; (c) cyclohexane; (d) cyclohexene. sections.

Only results obtained using pre-silylated packings are referred to in the following

Obtaining the thermodynamic results. Experimental results obtained on each column were fitted to the equation

$\ln V_{g}^{o}=-\Delta H_{s}^{\circ} / R T+$ constant

where $\Delta H_{s}^{\circ}$, the heat of sorption, corresponds to the transfer of one mole of solute from an ideal vapour phase at a partial pressure of 1 atm to an stationary phase of yet undefined characteristics. Regression analysis of the results obtained in a given column showed that: a) values of percent standard deviation of the heats of sorption, $100 \mathrm{~s}\left(\Delta \mathrm{H}_{\mathrm{s}}^{\circ}\right) / \Delta \mathrm{H}_{\mathrm{s}}^{\circ}$, were smaller than $1.5 \%$ for all the solutes; b) retention volumes obtained in a just conditioned column differed by less than $0.8 \%$ from those obtained under identical conditions after two or more weeks of column use, and the differences between the corresponding heats of sorption was smaller than $4 \%$.

In Fig. 2 and $3 V_{g}^{\circ}$ values at $25^{\circ} \mathrm{C}$ and heats of sorption, respectively, have been plotted against $w$ for a group of representative solutes. The existence of a mixed retention mechanism is made evident by both plots, since straight lines parallel to the horizontal axis should be obtained for a purely partitioning process; furthermore, it can advanced from Fig. 3 that the adsorptive component is markedly more exothermic than its solution counterpart [13]. 
Effect of thermal treatment on specific retention volumes, their temperature dependence and the efficiency of columns packed with Fomblin coated on Chromosorb P AW DMCS.

\begin{tabular}{lcccc} 
& \multicolumn{2}{c}{$\mathrm{n}$ - Decane } & \multicolumn{2}{c}{$\mathrm{n}$ - Nonane } \\
$\mathrm{w}=10.89 \%$ & PRE & POST & PRE & POST \\
$\mathrm{V}_{\mathrm{g}}^{\circ}, 45^{\circ} \mathrm{C}$ & 193.7 & 192.7 & 93.75 & 94.00 \\
$\mathrm{~V}_{\mathrm{g}}^{\circ}, 55^{\circ} \mathrm{C}$ & 129.9 & 129.2 & 65.32 & 65.64 \\
$\mathrm{~V}_{\mathrm{g}}^{\circ}, 70^{\circ} \mathrm{C}$ & 67.56 & 67.37 & 36.53 & 36.63 \\
$\mathrm{~B}$ & 4626 & 4663 & 4149 & 4170 \\
$\mathrm{~N}, 50^{\circ} \mathrm{C}$ & 1670 & 1450 & 1450 & 1200 \\
$\mathrm{~N}, 70^{\circ} \mathrm{C}$ & 1400 & 990 & 875 & 810 \\
& & & & \\
$\mathrm{w}=19.40 \%$ & & & & \\
$\mathrm{~V}_{\mathrm{g}}^{\circ}, 50^{\circ} \mathrm{C}$ & 115.5 & 113.42 & & \\
$\mathrm{~V}_{\mathrm{g}}^{\circ}, 62^{\circ} \mathrm{C}$ & 70.82 & 70.00 & & \\
$\mathrm{~V}_{\mathrm{g}}^{\circ}, 74^{\circ} \mathrm{C}$ & 44.64 & 44.82 & & \\
$\mathrm{~B}$ & 4506 & 4409 & & \\
$\mathrm{~N}, 50^{\circ} \mathrm{C}$ & 1260 & 1320 & & \\
$\mathrm{~N}, 74^{\circ} \mathrm{C}$ & 1300 & 1260 & &
\end{tabular}

PRE, POST: Results before and after the thermal treatment (details in the text).

$B$ : least squares slopes for the fit to the equation $\ln V_{g}^{0}=B / T+$ constant.

N: Number of theoretical plates.

Several years ago Conder et al. [14] proposed the following equation to express the retention volume per gram of packing when mixed mechanisms are operative:

$V_{N}=K_{L} V_{L}+K_{A} A_{L}+K_{S} A_{S}$

$K_{L}$ is the liquid-gas partition coefficient, $K_{A}$ and $K_{S}$ are the adsorption coefficients at the gasliquid and at the liquid-solid interfaces, respectively, and $V_{L}, A_{L}$ and $A_{S}$ represent the liquid volume, the gas-liquid interfacial area, and the liquid-solid interfacial area, all of them expressed per gram of packing; adsorption on bare portions of the support is not considered in eq. (3), what can be a reasonable attitude for packings containing more than 3-4 \% by weight of stationary phase on Chromosorb P. Models endeavouring more detailed descriptions, involving equations with larger number of terms and, as such, of more difficult and dubious applicability to real data, have been more recently proposed [15]. 


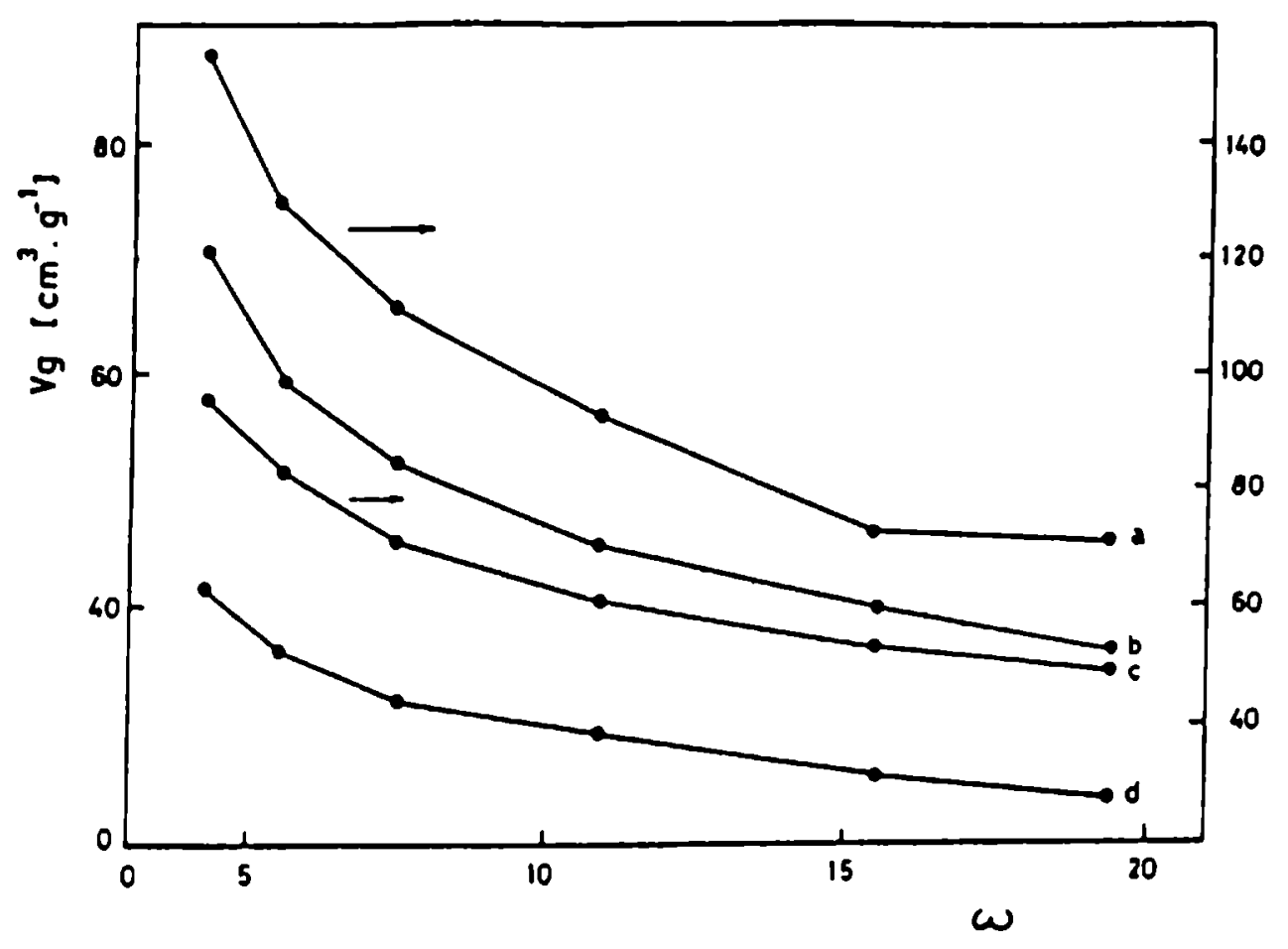

Fig. 2.- Specific retention volames at $25^{\circ} \mathrm{C}\left(V_{\mathrm{B}}^{0}\right)$ against percentage by weight of stationary phase (w). Solutes: (a) 1-octene; (b) n-heptane; (c) 2,2-dimethylhexane; (d) cycloherene.

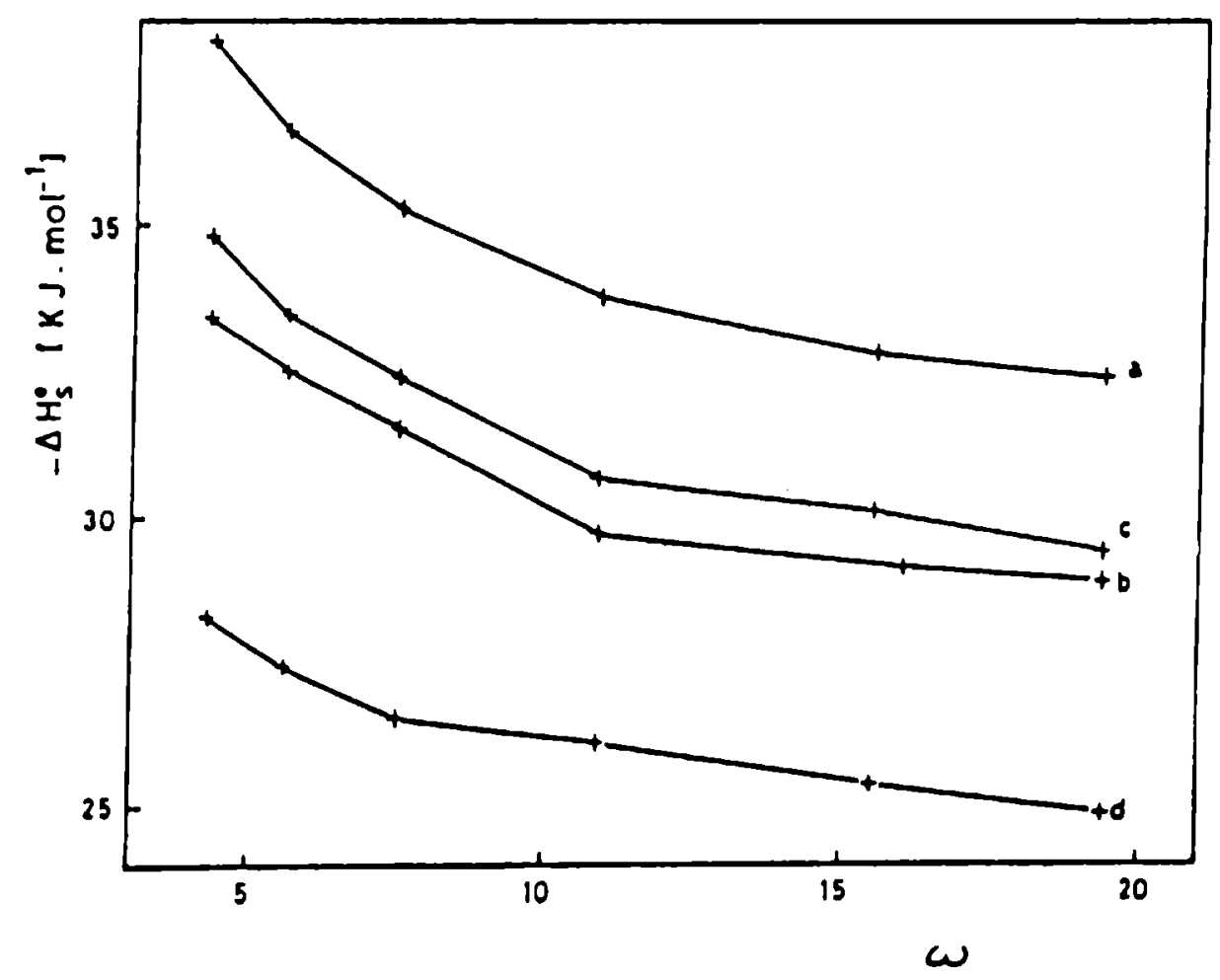

Fig. 3.- Heats of sorption $\left(\Delta H_{S}^{\circ}\right.$ ) against percentage by weight of stationary phase (w). Solute symbols as in Fig. 2.

The values of $A_{L}$ necessary to fit experimental results to eq. (3) were calculated by following the proposal of Martire et al. [16], taking into consideration the large difference between densities of $\beta, \beta^{\prime}$-thiodipropionitrile and of Fomblin.

Multiple linear regression to eq. (3), assigning to $A_{s}$ values calculated from the specific surface area of the support, was unsuccessfully attempted in the first place; the fit was insensible to very large changes in the values assigned to $A_{S}$, the coefficients had no statistical significance and, furthermore, it was found that eq. (3) was overparameterized, as evidenced by dependencies larger than 0.9999 . On the other side there was a good linear relationship 
between the variables $V_{N} / V_{L}$ and $A_{L} / V_{L}$, as indicated by correlation coefficients higher than 0.997 and by the small coefficients of variation of both the intercepts and the slopes (see second and fifth columns in Table $I$, respectively). In terms of eq. (3), since $V_{L}$ increases almost five times and $A_{L}$ decreases by about $60 \%$ between the lower and the higher stationary phase loading, it is reasonable to conclude that $K_{s}$ is negligible under the present circumstances. In other words, that within the experimental errors of our measurements, the intercepts and the slopes obtained by means of the linear regression can be identified with the coefficients $K_{L}$ and $K_{A}$, respectively.

These results indicate that hydrocarbons retention in columns containing Fomblin coated on Chromosorb P AW DMCS can be attributed to partition and adsorption on the gasliquid interface. Depending on the solute, adsorption contribution to the total retention ranges between 50-60\% at the lower loading and 10-15\% in the column with higher concentration of stationary phase, as calculated by using the $\mathrm{K}_{\mathrm{L}}$ and $\mathrm{K}_{\mathrm{A}}$ results obtained as indicated in the former paragraph together with the $V_{L}$ and $A_{L}$ values characteristic of each column.

Standard enthalpies of solution, corresponding to the transfer of one mole of solute from an ideal vapour phase at a pressure of $1 \mathrm{~atm}$ to an hypothetical solution at unitary weight fraction, with behaviour extrapolated from infinite dilution, were calculated by means of the equation [18]

$\Delta H_{L}^{\circ}=-R\left[\partial \ln K_{L} / \partial(1 / T)\right]-R T\left(1-\alpha_{2} T\right)$

The assumption of ideal vapour behaviour implied in eq. (4) is justified by a rapid calculation [12] which indicates that the nonideality correction in the case of the most volatile solute at the higher experimental temperature ( $\mathrm{n}$-hexane at $35^{\circ} \mathrm{C}$ ) amounts to about $0.3 \%$ of $\mathrm{K}_{\mathrm{L}}$, a value below our estimation of the experimental error.

Enthalpies of adsorption were computed from the expression

$\Delta H_{A}^{\circ}=-R\left[\partial \ln K_{A} / \partial(1 / T)\right]$

and it can be shown [19] that correspond to the transfer of one mole of solute from an ideal vapour phase at $1 \mathrm{~atm}$ to an ideal adsorbed state in which the molecules of adsorbate interact with the surface only. Inasmuch as adsorbate-adsorbate interactions are absent, the value of the adsorption enthalpy does not depend on the definition of the adsorbed state; this statement obviously does not apply to the adsorption free energy and entropy.

Solution and adsorption properties have been gathered in Table II. As already mentioned, the uncertainties assigned to $\mathrm{K}_{\mathrm{L}}$ and $\mathrm{K}_{\mathrm{A}}$ values are the standard deviations for the intercept and the slope, respectively, obtained in the regression of $V_{N} / V_{L}$ against $A_{L} / V_{L}$. The confidence ranges for $\Delta H_{L}^{\circ}$ and $\Delta H_{A}^{\circ}$ at the $95 \%$ level were estimated by following a method proposed some years ago [13], that takes into consideration that two successive regressions are necessary to obtain the enthalpy values. The latent heats of condensation, $\Delta H_{C}^{\circ}[20]$, were included in Table $\mathbf{I}$ with comparative purposes. 
U

동

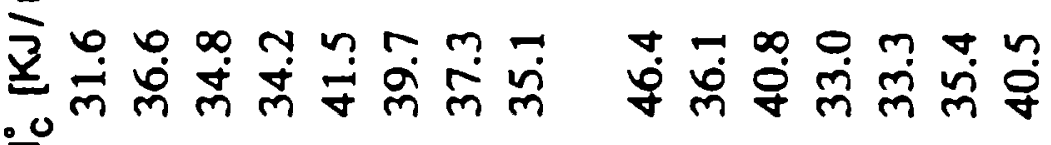

:0

$\overline{0}$

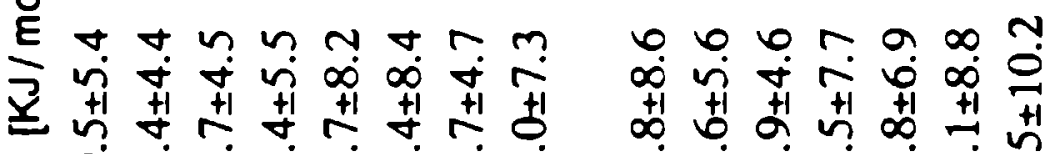

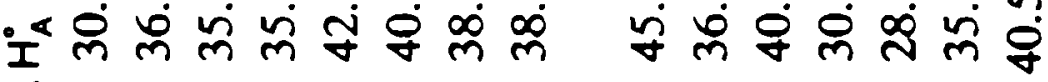

4

完

¿

至 产 ज़

$\underline{x}$

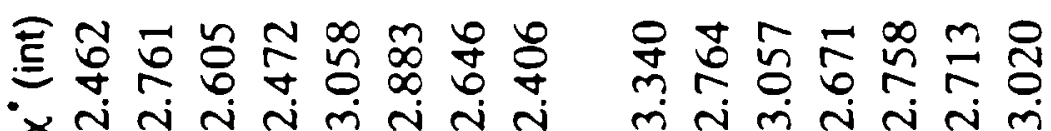

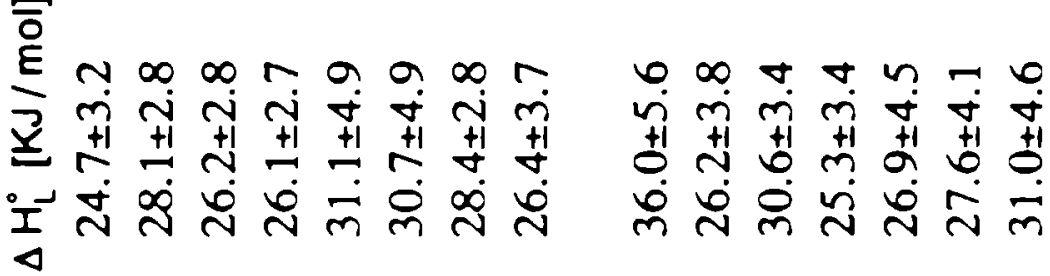

ษ ํำ

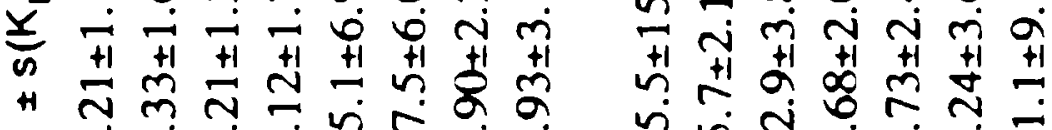

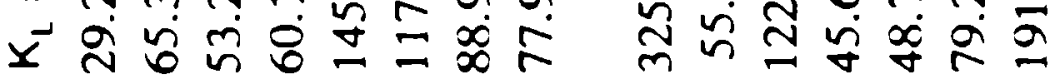

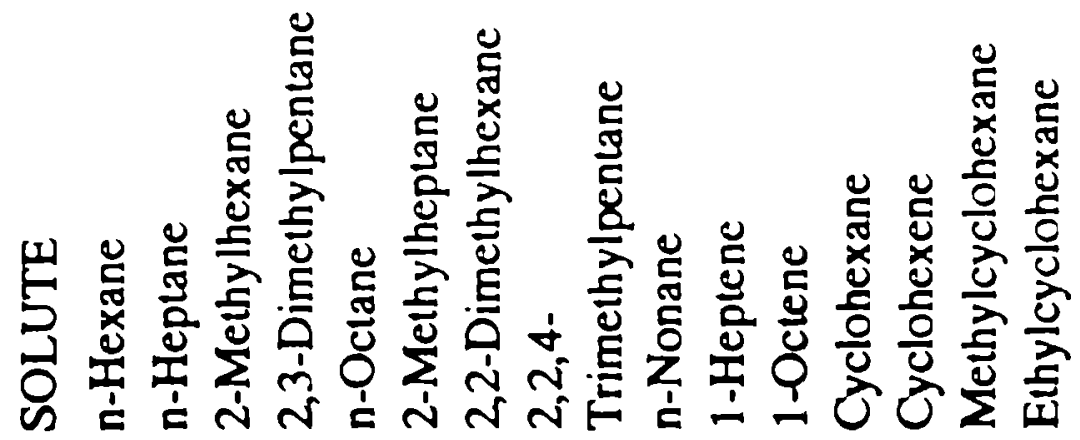


Results in the table change very regularly with the molecular structure of the solutes. Thus the plots of $\ln \mathrm{K}_{\mathrm{L}}$ for $\mathrm{n}$-alkanes against their carbon number, $\mathrm{N}$, are straight lines with correlation coefficients $r=0.99997$, and those of $\ln K_{A}$ against $N$ result in $r=0.9997$. Both $K_{L}$ and $K_{A}$ are smaller for branched than for normal alkanes with the same $N$, and (excepting the $K_{L}$ result for 2,3-dimethylpentane) both values decreases as branching increases. The alkenes partition coefficients are smaller than those of the corresponding alkanes, while the opposite trend is observed for the adsorption coefficients. Partition coefficients of cycloalkanes are larger than those of the alkanes with the same carbon number, but the adsorption coefficients of both groups of substances are coincident within experimental error.

As could be expected, a lower regularity is detected when the enthalpies are compared: plots of $\Delta H_{L}^{\circ}$ and of $\Delta H_{A}^{\circ}$ against $N$ for n-alkanes are well represented by straight lines, but their correlation coefficients drop to 0.994 and 0.991 , respectively. In general terms, branched alkanes and alkenes show less negative $\Delta H_{L}^{\circ}$ and $\Delta H_{A}^{\circ}$ values than normal alkanes with the same $\mathrm{N}$.

Figures 4 and 5 show that there is a strong correlation between $K_{A}$ and $K_{L}$ on one side, and between $\Delta H_{A}^{\circ}$ and $\Delta H_{L}^{\circ}$ on the other. It can be concluded from this behaviour that solution and adsorption are ruled by the same physical factors, either energetic or statistical. However, when the enthalpies of adsorption and of solution are compared with the latent heats of condensation it is found that :

a. the differences $\Delta H_{A}^{\circ}-\Delta H_{C}^{\circ}$ are zero within experimental error, indicating that the liquid-gas interface of Fomblin is a low energy surface on which the hydrocarbon molecules adsorb without experiencing the influence of large repulsion or attraction forces.

b. the differences $\Delta H_{L}^{\circ}-\Delta H_{C}^{\circ}$, rough estimators of infinite dilution excess enthalpies, range between 7 and $10 \mathrm{KJ} / \mathrm{mol}$, indicating that the solute molecules are repelled from the bulk liquid and demand the absorption of important quantities of energy in order to penetrate it.

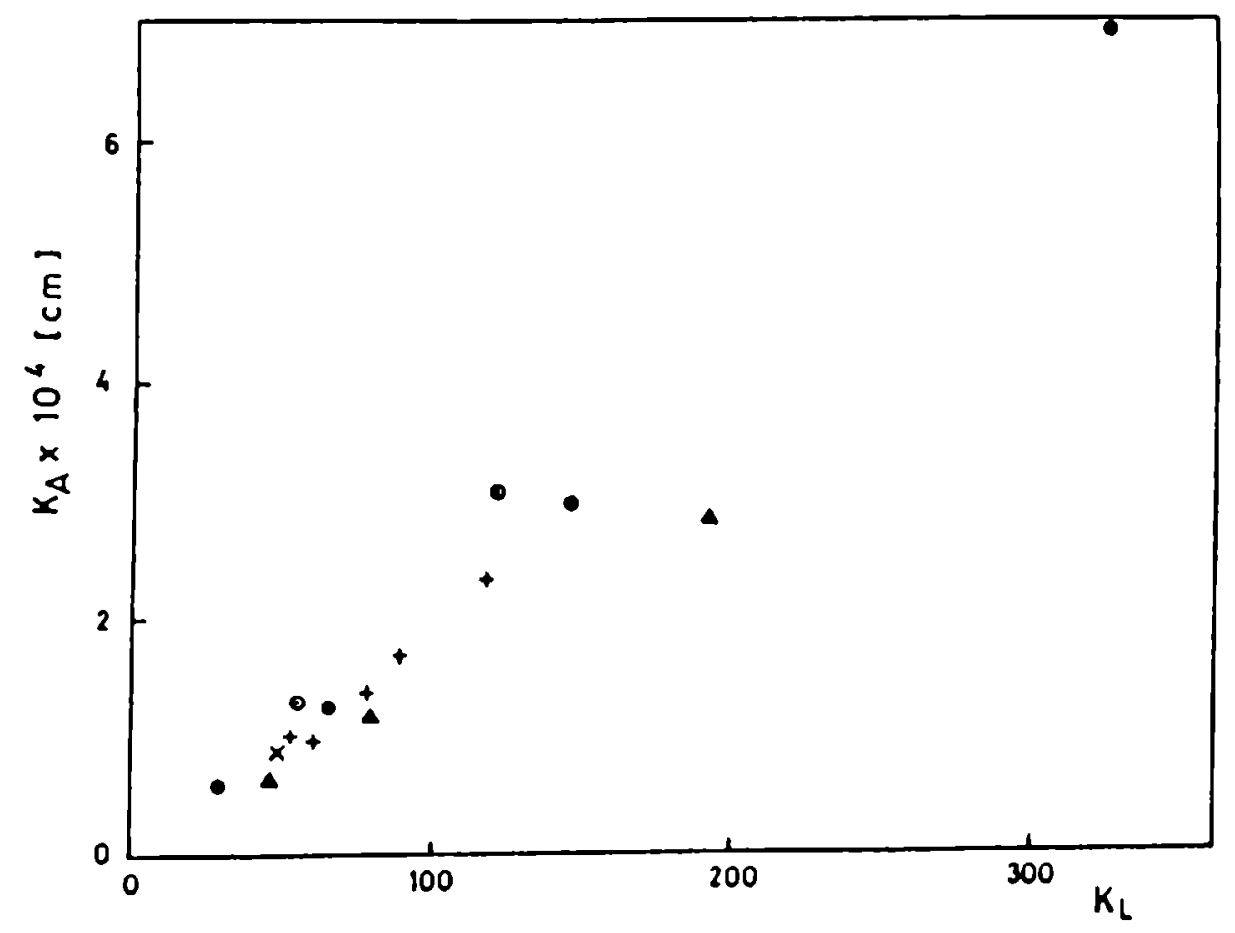

Fig. 4.- Adsorption coeffients $\left(K_{A}\right)$ against partition coefficients $\left(K_{L}\right)$ at $25^{\circ}$ C. Solutes: $(\bullet)$ n-alkanes; $(+)$ branched alkanes; (o) alkenes; $(\Delta)$ cycloalkanes; $(x)$ cyclohexene. 
Deviations from the ideal behaviour are more important in bulk mixtures than in surfaces, a fact already detected by Handa and Mukerjee [10], who attributed it to the lower number of nearest neighbours that a molecule has on the surface as compared to bulk solution. These authors semiquantitatively explained the surface properties of n-alkane + perfluoroalkane mixtures by assuming unitary surface activity coefficients and modeling the bulk activity coefficients by means of the regular solution or the Flory-Huggins approaches.

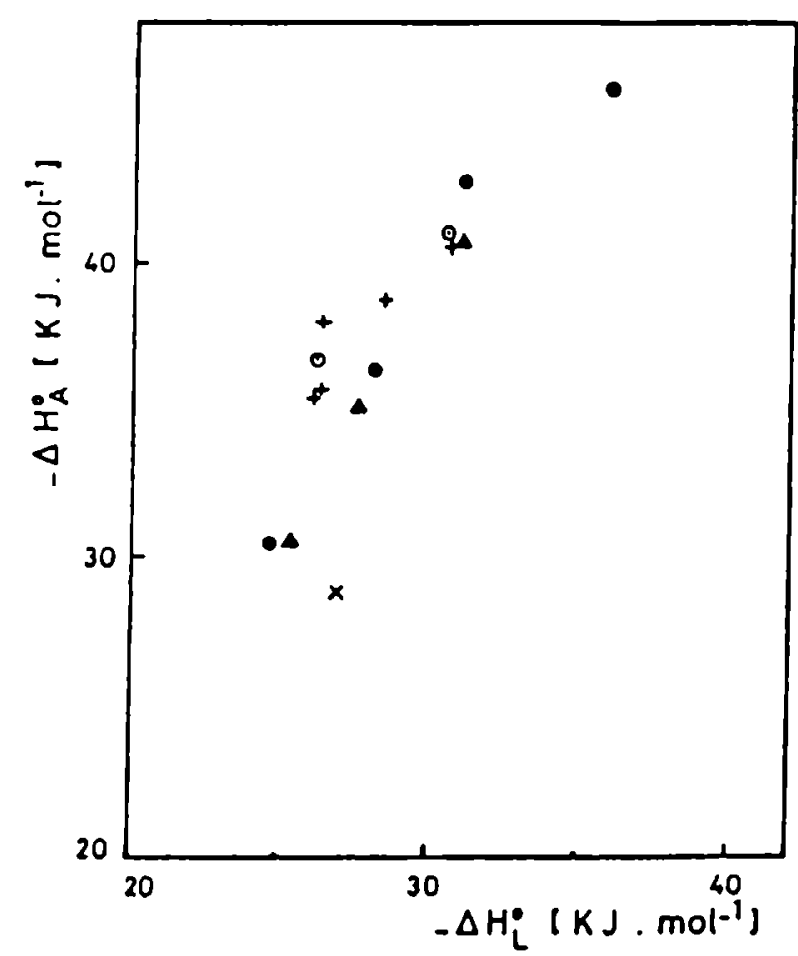

Fig. 5.- Enthalpy of adsorption $\left(\Delta H_{A}^{\circ}\right)$ against enthalpy of solution $\left(\Delta H_{L}^{\circ}\right)$. Symbols as in Fig. 4 .

Flory-Huggins interaction parameters, $\chi^{*}$, were calculated with the equation [21]

$\chi^{*}=\ln \left(R T \rho_{2} / K_{L} p_{1}^{0} M_{1}\right)-\ln \left(v_{1}^{*} / v_{2}^{*}\right)-1+\left(M_{1} v_{1}^{*} / M_{2} v_{2}^{*}\right)$

where $M_{1}$ and $p_{1}^{\circ}$ represent the solute molecular weight and vapour pressure at the column temperature, respectively, $M_{2}$ is the polymer number average molecular weight and $v_{1}^{*}$ and $v_{2}^{*}$ are the solute and the polymer specific "hard core" volumes, calculated by means of Flory state equation [22] using experimental thermal expansion coefficients. The interaction parameter is an adimensional free energy term that includes all the non-combinatorial contributions to excess free energy; Flory and collaborators [22] express $\chi^{*}$ as a sum of two contributions:

$\chi^{*}=\chi^{*}(\mathrm{fv})+\chi^{*}$ (int)

$\chi^{*}(\mathrm{fv})$ is the free volume contribution, and $\chi^{*}$ (int) results from contact interactions.

Unusually high $\chi^{*}$ values, ranging between 2.4 and 3.4, are obtained for the systems studied in the present paper. With the only exception of n-hexane, free volume effects contribute less than $2.5 \%$ to the total interaction parameter. The highly positive nonideality of these mixtures results from very large differences between the force fields surrounding the hydrocarbon and the perfluorocarbon segments. 
Values of $\chi^{*}$ (int) can be read on the fourth column of Table II; they were fitted by a non-linear regression method to the equation

$\chi^{*}$ (int) $=\left(V_{1}^{*} / R T\right)\left(\delta_{1}-\delta_{2}\right)^{2}$

where $V_{1}^{*}=M_{1} v_{1}^{*}, \delta_{1}$ is the solute solubility parameter [23] and $\delta_{2}$, the polymer solubility parameter, was the fitting parameter. A value $\delta_{2}=7.65 \mathrm{~J}^{1 / 2} \cdot \mathrm{cm}^{-3 / 2}$ is thus obtained; the standard deviation obtained for $\delta_{2}$ is only $0.084 \mathrm{~J}^{1 / 2} \cdot \mathrm{cm}^{-3 / 2}$, indicating that the experimental results fit nicely to eq.(8). However the value returned for $\delta_{2}$ is unusually low and, from our point of view, its physical meaning is not clear. This is by no means a novelty in dealing with polymer solubility parameters.

\section{ACKNOWLEGEMENT}

This work was sponsored by CONICET (Consejo Nacional de Investigaciones Científicas y Tecnológicas) through PID-BID 1121, and by CICPBA (Comisión de Investigaciones Científicas de la Provincia de Buenos Aires)

\section{REFERENCES}

[1] Pomaville R.M. and Poole C.F.- Anal. Chim. Acta, 200, 151 (1987).

[2] O' Mahony T.K.P., Cox A.P. and Roberts D.J.- J. Chromatogr., 637, 1 (1993).

[3] Hildebrand J.H., Prausnitz J.M. and Scott R.L.- Regular and Related Solutions, Van Nostrand-Reinhold, New York, 1970.

[4] Bedford R.G. and Dunlap R.D.- J. Am. Chem. Soc., 80, 282 (1958).

[5] Dunlap R.D., Bedford R.G., Woodbrey J.C. and Furrow S.D.- J. Am. Chem. Soc, 81 2927 (1959).

[6] Dhanesar S.C. and Poole C.F.- J. Chromatogr., 267, 388 (1983).

[7] Dhanesar S.C. and Poole C.F.- Anal. Chem., 55, 1462 (1983).

[8] Scott R.L.- J. Phys. Chem, 62, 136 (1958).

[9] Swinton F.L.- In M. L. McGlashan (Editor), Chemical Thermodynamics, Specialist Periodical Reports, Chemical Society, London, 1978, Vol. 2, 147.

[10] Handa T. and Mukerjee P.- J. Phys. Chem, 85, 3916 (1981).

[11] Mukerjee P.- Colloid Surface A, 84, 1 (1994). 
[12] Conder J.R. and Young C.L.- Physicochemical Measurements by Gas Chromatography, Wiley, New York, 1979, Ch. 2.

[13] Castells R.C.- J. Chromatogr., 111, 1 (1975).

[14] Conder J.R., Locke D.C. and Purnell J.H.- J. Phys. Chem, 73, 700 (1969).

[15] Nikolov R.- J. Chromatogr., 241, 237 (1982).

[16] Martire D.E., Pecsok R.L. and Purnell J.H.- Trans. Faraday Soc, 61, 2496 (1965).

[17] Martin R.L.- Anal. Chem, 33, 347 (1961).

[18] Castells R.C.- J. Chromatogr., 350, 339 (1985).

[19] Meyer E.F.- J. Chem. Educ, 57, 120 (1980).

[20] Dreisbach R.R.- Adv. Chem. Ser. 15 (1955); 22 (1959).

[21] Patterson D., Tewari Y.B., Schreiber H.P. and Guillet J.E.- Macromolecules 4, 356 (1971).

[22] Eichinger B.E. and Flory P.J.- Trans. Faraday Soc., 64, 2035 (1968).

[23] Barton A.F.M.- Handbook of Solubility Parameter, CRC Press, Boca Raton, Florida, 1983. 
